\title{
The Economic Policy Uncertainty in China, the United States, and Europe: The Empirical Impact on Chinese Stock Markets
}

\author{
Wannakomol Supachart ${ }^{1}$ \\ ${ }^{1}$ The School of Economics, Shanghai Univerity, Shanghai, 200444, China \\ Correspondence: Wannakomol Supachart, The School of Economics, Shanghai Univerity, Shanghai, 200444, China.
}

Received: July 8, 2019

Accepted: July 31, $2019 \quad$ Available online: August 13, 2019

doi:10.11114/aef.v6i5.4370

URL: https://doi.org/10.11114/aef.v6i5.4370

\begin{abstract}
The objective of this paper is to analyze the impact of economic policy uncertainty (EPU) in China, the United States, and Europe, which are influent to the Chinese stock markets. We employed Vector Autoregression (VAR) model with relative variables including the EPU indices and three Chinese stock markers indices to display the impulse responses of the markets to the EPUs. Our results indicate that the Chinese stock markets negatively respond to their domestic economic policy uncertainty in the first, second, and third month after the EPU shocks. Moreover, we also found the negative responses of the Chinese markets to the EPU from the United States that require five months to rebalance the markets. However, the Chinese markets seem positively respond to the shocks of the economic policy uncertainty in Europe and also took five months to archive market rebalancing. The significant correlation of the economic policy uncertainty between China and the United States resulted in cross-sectional correlation estimates among the EPU indices. Furthermore, there is the reasonable interesting result to claim that the economic policy uncertainty in China is statistically influenced by their own trade and fiscal policy uncertainty that may be considered to be related with China-US trade war in our conclusion.
\end{abstract}

Keywords: EPU, economic policy uncertainty, China, stock market, VAR

\section{Introduction}

China has become the world's second-largest economy and its GDP is the largest in the world if it was measured by purchasing power parity (PPP). The economic reform for over forty years since it was initiated in 1978, led China lifting out of the poverty and brought dramatic high-technology development. The combination between industrialization and urbanization has also helped China turning to be an influent market in the world. However, the gradual growth of the Chinese economy has been slow down since 2012 and reached the lowest of economic growth rate since 1990 at 6.3 percent by the end of 2018. The economic policy made by the Chinese government has yet contributed to the uncertainty especially when China and the United States has faced trade-war that requires both countries for the policy adjustment to settle the conflict circumstances.

The uncertainty is something unexpectable to happen. In other word, it could be said that uncertainty is an unpredictable phenomenon in the future that will be resulted in unexpected consequences. The economic uncertainty produces most of negative effect on economic activities leading to the large persistent reductions in production and employment (Bachman, Elstner \& Sims, 2013). A rise in uncertainty indeed depresses real economic activities such as output and employment (Yun \& Luk, 2018) especially the economic policy uncertainty (EPU) in the United States, Europe, and China that accounted two-third of total negative effects reducing world economic activities (Biljanovska, Grigoli \& Hengge, 2017). The concerns regarding China's competition with the US in shaping the global world order are more likely to be driven by political factors rather than economic motives (Zhang, Lei, Ji \& Kutan 2018). Thereupon, changes in economic policy in China implied to the economic uncertainty has urged various sectors to prepare in order to have the readiness for further actuation. Consider the global economic policy uncertainty index, it reveals an increase in the world's aggregate economic policy uncertainty since mid-2007 as well as EPU indices in the US and China. The Chinese EPU index reached the peak at the end of 2018, the same time as the economic growth in China was at the lowest rate and occurred with an emerging of the serious trade-war. 


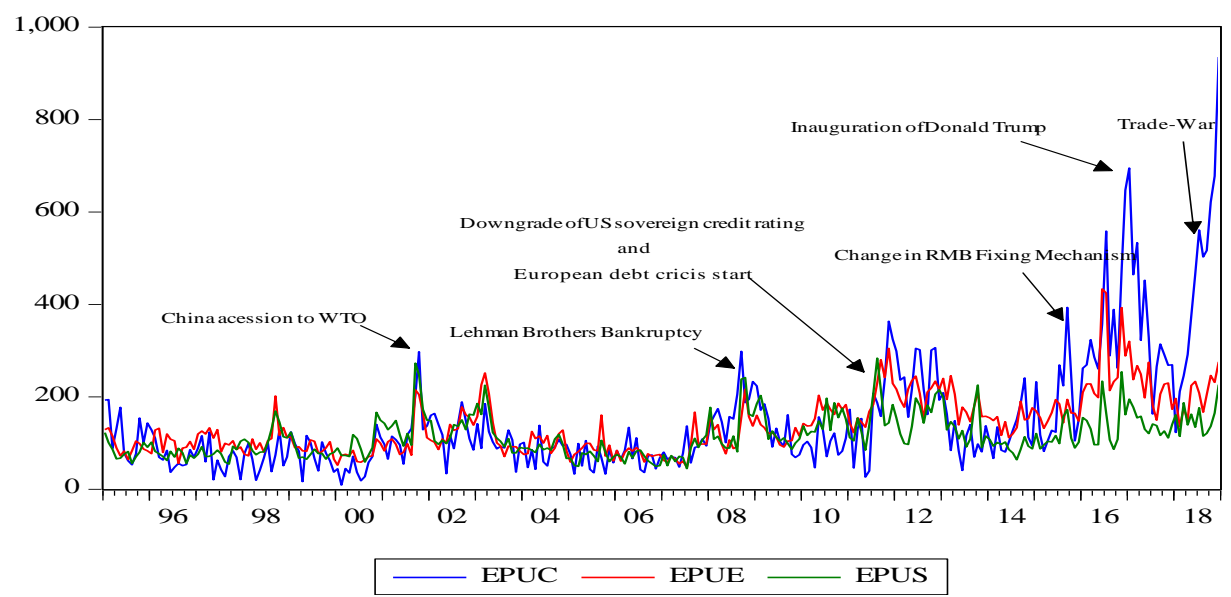

Figure 1. The co-movement among uncertainty indices in China, Europe, and the US

The abbreviation of EPUC, EPUE, and EPUS are respectively abbreviated for economic policy uncertainty index in China, Europe, and the United States. The EPUs in Figure 1 are seemingly sharply-increased behind several financial events, for example, the collapse of Lehman Brothers in 2008, US sovereign credit rating downgrade and European Debt Crisis in 2011, changes in RMB fixing mechanism in 2015, or the current endless trade-war that began in mid-2018. It could be seen the co-movement among international EPUs especially from the US and Europe, as well as Chinese domestic EPU, are likely to be related to the dramatic decreases of Chinese stock market indices apparently in 2008 and 2015, the tendentious timelines of major financial events whilst the EPUs have reached the peaks.

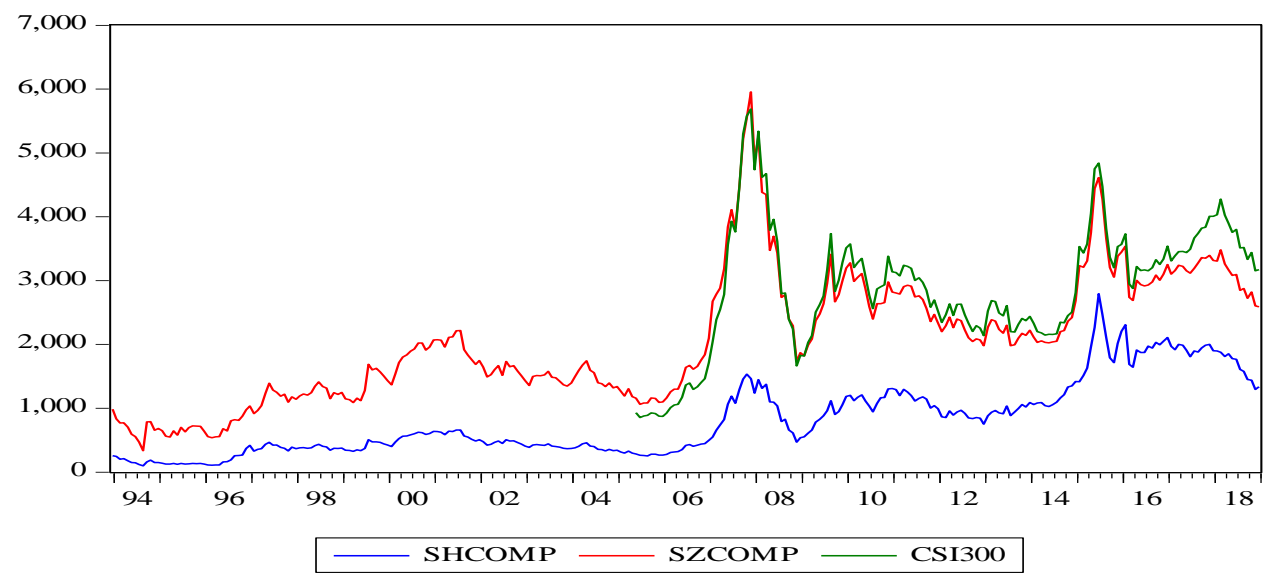

Figure 2. Chinese stock market indices ${ }^{1}$

As investors in the financial market expect their returns according to the risk taken by the uncertainty that plays important role in order of decision making under information they received as well as a corporate investment which degree of marketization is sensitive to the economic policy uncertainty (Wang, Chen \& Huang2014). Thus, we may consider that EPU affects not only in the real economy but also create significant reactions from the financial market by comparing time path of graphs in Figure 1 and Figure 2. It is consistent with many literatures that revealed the negative relationship between arising of economic policy uncertainty and lower stock market return. On the other hand, uncertainty could make a positive effect if the government responds properly to unanticipated shocks (Pastor \& Veronesi, 2013).

${ }^{1}$ CSI 300 is a capitalization-weighted stock market index designed to replicate the performance of top 300 stocks traded in the Shanghai and Shenzhen stock exchanges. This index has been calculated since April 8th, 2005 and the first index figure in database is available by May 2005. 
According to significant changes of EPU during the past five years (2014-2018) together with changes in the returns of the Chinese key stock markets, we were interested to study the influence of EPU from foreign regions (Europe and US) and domestic China's EPU that may have dynamic effects on the Chinese stock markets by showing data characteristics and their cross-sectional coefficients. Furthermore, we employ the standard Vector Autoregression (VAR) to demonstrate the impulse responses of Chinese stock markets to the changes of EPUs.

\section{Literature Review}

An alternative measure of economic uncertainty using the new base forecasting in h-periods ahead was developed by Jurado, Sydney, and Serena (2015). This time-varying of macroeconomic uncertainty estimation methodology has gained popularity according to the findings of a significant shock that played a role in the business cycle. Apart from literature of Jurado et al. (2015) which particularly focused on overall macroeconomic uncertainty and macroeconomic activities, Baker, Bloom, Davis (2016) developed a new specified index of economic policy uncertainty (EPU) by using newspaper-based measurement on VAR process to give a demonstration of the economic policy uncertainty that was economically associated with an increasing of stock price volatility, and reduced investment the financial market. This EPU index has been widely used in many researches due to the ability of making an effect in the stock market. It is likewise capable to indicate the impact of economic uncertainty in the particular policy level that plays a role in the financial market. In the stock market, higher EPU leads to significant increasing in market volatility by expected return predictability (Liu \& Zhang, 2015). The policy news is the major source of market volatility that was later explained by the newspaper-based of Equity Market Volatility (EMV) tracking with the Chicago Board Option Exchange (COEB)'s volatility index (VIX) which is mostly influenced by fiscal policy and monetary policy in taxes (Baker, Bloom, Davis \& Kostd, 2019). Furthermore, it also influenced the market liquidity during normal market condition as well as during the financial crisis (Debata \& Mahakud, 2018).

Regarding most of literature reviews for this paper, we considered the Vector Autoregression (VAR) model which is famous and popularly used in many empirical studies that related to the EPU and stock market. A grateful appreciation of contribution for this successful econometric model must be given to Sims (1980) as well as Hamilton (1994) who introduced VAR models and its application to financial data. The model is flexible because conditional forecast of specific variables can be estimated under theoretical frameworks. Based on VAR, Sum (2012) investigated how stock market returns responded to the EPU shocks that resulted in negative responses in the first, fourth, fifth, eighth, night, tenth and eleventh months. This investigation also indicated the statistical negative relationship between EUP and the returns of stock markets in European Union countries. Nevertheless, there is an evidence from the United States that revealed the negative long-run relationship between the EPU and US stock markets. Working with long time series data from 1900 to 2014, Arouri, Estay, Rault, and Roubaud (2016) found reduction of stock returns in the US markets affected by an increase in the EPU. The effect was stronger persistent particularly when market volatility was extreme. In addition, the EPU could also draw a negative influence in the U.S. stock-bond market correlation with long-term investors in corresponding results from Fang, Yu, and $\mathrm{Li}$ (2017).

The EPU shocks from the US significantly produced negative returns in the Pacific Rim countries stock markets, Canada, China, Japan, Korea, and the US. It was confirmed by Christou, Cunado, Gupta, and Hassapis (2017) with the comparative of the standard VAR and Bayesian Panel VAR (BPVAR). The literature also claimed that the stock market in Australia was the only one of the samples that have no significant negative response from the US's EPU shocks, explained under their foreign-domestic EPU spillover concept. Thus, there were opportunities for investors to gain from investing in Australian market while economic policy uncertainty in the United States was increasing. In China, many researchers have concerned about economic policy uncertainty shocks especially one from the United States which has been emphasized in many literatures as it could produce negative impact on Chinese real economy in both firm and macro level as well as the stock market. It was clarified by an empirical evidence of stock market correlation that was driven by EPU in cross- international context. ARCH model statistics in Li and Peng (2017) showed that an increase in EPU from the US negatively affected the co-movements of Chinese A/B stocks and the US stock market. Furthermore, the statistical spillover effect of the EPU in China's real economy was found during bust cycle under Smooth Transition Vector Autoregression (STVAR) estimation to underline that the Chinese EPU is a determinant of the economic policy uncertainty and unemployment in the US (Fontaine, Didier \& Razafindravaosolonirina, 2017). Beside that negative responses of the Chinese stock market to the EPU, it has been discussed that the EPU can also negatively predict expected future returns of the Chinese market. This was strongly corroborated by designing an asset pricing model under short-sales constraint (Chen, Jiang, and Tong, 2017) resulted in a large fluctuation during the financial crisis in particular greater effect in Shanghai comparing with Shenzhen stock market (Xiong, Bian \& Shen, 2018). 


\section{Data}

To measure economic policy uncertainty, we used the economic policy index (EPU) constructed by Baker et al., (2016) as the proxy of economic policy uncertainty. The monthly time-series data was considered regarding suggestions from many literature reviews, in particular, Patton and Ramadorai (2013) who suggested to use high-frequency data to capture time-series variation of market exposure to risk factor which have significance across months. Data of the variables in this study were retrieved from two online sources; (1) the economic policy uncertainty indices and related uncertainty factors were pulled from http://www.policyuncertainty.com and (2) Chinese three stock market indices from CEIC database which including Shanghai Composite Index (SHCOMP), Shenzhen Composite Index (SZCOMP), and the weighted index between Shanghai and Shenzhen markets (CSI300) to represent the performance of Chinese stock markets while the economic policy uncertainty in China (EPUC), Europe (EPUE), and the United States (EPUS) will be carefully focused to analyze the impacts on these markets with the following data statistic summarized in Table 1. However, due to the data availability for CSI300 and all variable will be estimated based on logarithm in order to explain the percentage of changes in explanatory and responses variables in VAR model, number of observations will be expected to be 162 after data adjustment.

Table 1. Data summary

\begin{tabular}{lrrrrrr}
\hline & \multicolumn{1}{c}{ CSI300 } & SHCOMP & SZCOMP & \multicolumn{1}{c}{ EPUC } & \multicolumn{1}{c}{ EPUE } & EPUS \\
\hline Mean & 2886.511 & 817.6638 & 2068.736 & 148.0164 & 136.4262 & 113.4360 \\
Median & 2919.380 & 602.0620 & 1979.210 & 105.0337 & 119.6869 & 102.0150 \\
Maximum & 5688.543 & 2793.254 & 5954.770 & 935.3103 & 433.2775 & 283.6656 \\
Minimum & 855.950 & 96.561 & 333.900 & 9.066 & 47.6927 & 44.7839 \\
Std. Dev. & 993.2155 & 583.1196 & 1011.9996 & 128.4427 & 63.0696 & 44.1958 \\
Skewness & 0.0397 & 0.9112 & 0.7681 & 2.4718 & 1.3554 & 1.1596 \\
Kurtosis & 3.2243 & 2.9267 & 3.6740 & 10.9655 & 5.7772 & 4.2533 \\
Observations & 164 & 301 & 301 & 288 & 301 & 301 \\
\hline
\end{tabular}

Nonetheless, China's economic policy uncertainty index (EPUC) measure by Baker, Bloom, Davis, and Wang (2013) will also be estimated under time-varying OLS to estimate the impacts of sub-policy key factors including uncertainty of Chinese exchange rate (CN_EXR), uncertainty of fiscal policy in China (CN_FISCAL), uncertainty of monetary policy in China (CN_MONETARY), and uncertainty of trade policy in China (CN_TRADE). In this part, monthly data samples were adjusted from January 2000 to December 2018 with 228 observations.

\section{Methodology}

In this paper, we employed the standard VAR (p) with our variables (will be described in the next part) which are (1) SHCOMP, (2) SZCOMP, (3) CSI300, (4) EPUC, (5) EPUE, and (6) EPUS. In order to fit the stationary VAR, Augmented Dicky-Fuller (ADF) unit-root test will be used to test the stationary of data before approaching VAR process;

Let $Y_{t}=\left(y_{1 t}, y_{2 t}, \ldots, y_{n t}\right)^{\prime}$ denote an $(n \times 1)$ vector of time-series variables with the basic p-lags vector autoregressive $(\operatorname{VAR}(\mathrm{p}))$ model that has the form

$$
\mathrm{Y}_{t}=c+\prod_{1} \mathrm{Y}_{t-1}+\prod_{2} \mathrm{Y}_{t-2}+\cdots+\prod_{p} \mathrm{Y}_{t-p}+\varepsilon_{t}, t=1, \ldots, T
$$

where $\Pi_{i}$ are $(n \times n)$ coefficient matrices and $\varepsilon_{t}$ is an $(n \times 1)$ unobservable zero mean white noise vector process with time invariant covariance matrix $\Sigma$. Then, the arrangement of sample data in deterministic terms in this study to fit $\operatorname{VAR}(\mathrm{p})$ will be

$$
\begin{gathered}
\left(\begin{array}{c}
\operatorname{SHCOM}_{t} \\
\vdots \\
\text { EPUS }_{t}
\end{array}\right)=\left(\begin{array}{c}
c_{1} \\
\vdots \\
c_{6}
\end{array}\right)+\left(\begin{array}{ccc}
\pi_{11}^{1} & \cdots & \pi_{16}^{1} \\
\vdots & \ddots & \vdots \\
\pi_{61}^{1} & \cdots & \pi_{66}^{1}
\end{array}\right)\left(\begin{array}{c}
\operatorname{SHCOMP}_{t-1} \\
\vdots \\
\operatorname{EPUS}_{t-1}
\end{array}\right)+\left(\begin{array}{ccc}
\pi_{11}^{2} & \cdots & \pi_{16}^{2} \\
\vdots & \ddots & \vdots \\
\pi_{61}^{2} & \cdots & \pi_{66}^{2}
\end{array}\right)\left(\begin{array}{c}
\operatorname{SHCOMP}_{t-2} \\
\vdots \\
\operatorname{EPUS}_{t-2}
\end{array}\right) \\
+\left(\begin{array}{ccc}
\pi_{11}^{p} & \cdots & \pi_{16}^{p} \\
\vdots & \ddots & \vdots \\
\pi_{61}^{p} & \cdots & \pi_{66}^{p}
\end{array}\right)\left(\begin{array}{c}
\operatorname{SHCOMP}_{t-p} \\
\vdots \\
\operatorname{EPUS}_{t-p}
\end{array}\right)+\left(\begin{array}{c}
\varepsilon_{1 t} \\
\vdots \\
\varepsilon_{6 t}
\end{array}\right)
\end{gathered}
$$


and the lag operator notation of VAR (p) is written as

$$
\Pi(L) \mathrm{Y}_{t}=c+\varepsilon_{t} \quad ; \Pi(L)=\mathrm{I}_{n}-\Pi_{1} L-\ldots-\Pi_{p} L^{p}
$$

\subsection{Lag Length Selection}

Once the estimation was obtained from $\operatorname{VAR}(\mathrm{p})$ process, the lag length selection will be determined upon model selection criteria which have form

$$
\operatorname{IC}(p)=\ln |\tilde{\Sigma}(p)|+c_{T} \cdot \varphi(n, p)
$$

where $\tilde{\Sigma}(p)=T^{-1} \Sigma_{t=1}^{T} \hat{\varepsilon}_{t} \hat{\varepsilon}_{t}^{\prime}$ is the residual covariance matrix without a degree of freedom correlation from $\operatorname{VAR}(\mathrm{p})$, $c_{T}$ is a sequence indexed by the sample size $T$, and $\varphi(n, p)$ is a penalty function which penalizes large $\operatorname{VAR}(\mathrm{p})$ models. Hence, lag length selection of the model in this study will be considered by using the most common information criteria which are the Akaike (AIC), Schwarz-Bayesian (BIC), and Hannan-Quinn (HQ) that come with the highest absolute value regarding.

$$
\begin{aligned}
& A I C(p)=\ln |\tilde{\Sigma}(p)|+\frac{2}{T} p n^{2} \\
& B I C(p)=\ln |\tilde{\Sigma}(p)|+\frac{\ln T}{T} p n^{2} \\
& H Q(p)=\ln |\tilde{\Sigma}(p)|+\frac{2 \ln \ln T}{T} p n^{2}
\end{aligned}
$$

\subsection{Impulse Responses}

Regarding the representative of VAR in equation (1), the impulse responses of the Chinese stock markets with respect to the shocks (EPUC, EPUE, and EPUS) at the horizon $h$ of the variables to an exogenous shocks to variables $j$ will be

$$
\frac{\partial Y_{t+h}}{\partial \varepsilon_{\mathrm{j}, t}}=\frac{\partial}{\partial \varepsilon_{\mathrm{j}, t}}\left(\prod Y_{t+h-1}+\varepsilon_{t+h-1}\right)=\cdots=\frac{\partial}{\partial \varepsilon_{\mathrm{j}, t}}\left(\prod^{h+1} Y_{t}+\sum_{i=1}^{h} \Pi^{i} \varepsilon_{t+h-i}\right)
$$

The derivative equation will eliminate all terms but one, namely the term in the sum which is $\prod_{\varepsilon_{t}}^{h}$, for which we get

$$
\frac{\partial Y_{t+h}}{\partial \varepsilon_{\mathrm{j}, t}}=\frac{\partial}{\partial \varepsilon_{\mathrm{j}, t}}\left(\Pi^{h+1} Y_{t}+\sum_{i=1}^{h} \Pi^{i} \varepsilon_{t+h-i}\right)=\frac{\partial}{\partial \varepsilon_{\mathrm{j}, t}} \Pi^{h} \varepsilon_{t}=\Pi^{h} e_{j}
$$

where $\varepsilon_{j}$ is the $j^{\text {th }}$ row of the power $n \times n$ identity matrix that is the responses of all $n$ variable at the horizon

$h$ to shock variable $j$ in the $j^{\text {th }}$ column of $\Pi^{h}$.

\section{Empirical Results}

\subsection{China's EPU Components}

According to our database, so we consider China's EPU (EPUC) to be in four policy categories of uncertainty which are exchange rate, fiscal, monetary, and trade. We assume that Chinese EPU would statistically relate to at least one of mentioned categorial EPUs. Thus, firstly, we applied these factors into an ordinary linear regression model to investigate degree of these sub-uncertainties as:

$$
E P U C_{t}=\alpha_{t}+\beta_{1} C N_{-} X E R_{t}+\beta_{2} C N_{-} F I S C A L_{t}+\beta_{3} C N_{-} M O N E T A R Y_{t}+\beta_{4} C N_{-} T R A D E_{t}+\varepsilon_{t}
$$

The result obtained from an estimation of equation (10) reveals that trade and fiscal policy uncertainty in China are the major component producing their economic policy uncertainty. The statistic coefficients displayed in Table 2 demonstrate that trade policy uncertainty in China (CN_TRADE) is the most influent factor by 64.8 percent, followed by fiscal policy uncertainty (CN_FISCAL) that could affect an increasing the Chinese EPU (EPUC) around 58 percent. 
Table 2. The components of China's economic policy uncertainty

\begin{tabular}{lllll}
\hline Dependent Variable: EPUC & & & & \\
\hline Variable & Coefficient & Std. Error & t-Statistic & Prob. \\
\hline CN_EXR & 0.28934 & 0.19919 & 1.45253 & 0.14780 \\
CN_FISCAL & $0.58474 * * *$ & 0.20997 & 2.78495 & 0.00580 \\
CN_MONETARY & -0.44988 & 0.29548 & -1.52256 & 0.12930 \\
CN_TRADE & $0.64829 * * *$ & 0.07943 & 8.16199 & 0.00000 \\
alpha & 41.15929 & 16.70409 & 2.46403 & 0.01450 \\
\hline
\end{tabular}

Note: $*, * *$, and $* * *$ in the table represent the confidence levels at $90 \%, 95 \%$, and $99 \%$ in respectively.

\subsection{Correlation of the Variables}

Considering cross-sectional correlation among the variables in

Table 3, Shenzhen stock market is slightly more correlated to the CSI300 index than Shanghai market around 18 percent. This was demonstrated by the first and second rows of the first column in the table showing the number of 0.7585 and 0.9689 which are the power of correlation between respective Shanghai and Shenzhen composite index with CSI300. It could be also seen that market indices from Shanghai (SHCOMP) and Shenzhen (SZCOMP), as well as their weighted index of 300 blue-chip stocks (CSI300) are statistically related to China's EPU (EPUC), respectively revealed by $0.4742,0.1353$, and 0.2458 of confident correlation coefficients. Nevertheless, the foreign uncertainty from the United States (EPUS) and Europe (EPUE) significantly correlate only with Shanghai composite and CSI300 index to but this result was not statistically found in the Shenzhen market.

Table 3. Cross-sectional correlation matrix

\begin{tabular}{lllllll}
\hline $\begin{array}{l}\text { Correlation } \\
\text { [t-Statistic] }\end{array}$ & CSI300 & SHCOMP & SZCOMP & EPUC & EPUE & EPUS \\
\hline CSI300 & 1.00000 & & & & & \\
SHCOMP & $0.78580^{* * * *}$ & 1.00000 & & & & \\
& {$[16.1710]$} & & & & & \\
SZCOMP & $0.96891^{* * *}$ & $0.70002 * * *$ & 1.00000 & & & \\
& {$[49.8470]$} & {$[12.4766]$} & & & & \\
EPUC & $0.24858^{* * *}$ & $0.47426^{* * *}$ & $0.13533^{*}$ & 1.00000 & & \\
& {$[3.2664]$} & {$[6.8565]$} & {$[1.7385]$} & & & \\
EPUE & $0.24427 * * *$ & $0.53405^{* * * *}$ & 0.11257 & $0.68764 * * *$ & 1.00000 & \\
& {$[3.2062]$} & {$[8.0399]$} & {$[1.4419]$} & {$[12.0544]$} & & \\
EPUS & $0.18541^{* *}$ & $0.24306^{* * *}$ & 0.07528 & $0.47849 * * *$ & $0.69284 * * *$ & 1.00000 \\
& {$[2.4015]$} & {$[3.1893]$} & {$[0.9609]$} & {$[6.9358]$} & {$[12.2291]$} & \\
\hline
\end{tabular}

Note: *,*, and $* * *$ in the table represent the confidence levels at $90 \%, 95 \%$, and $99 \%$ in respectively

Moreover, the comparative analysis of Chinese market indices and their domestic economic policy uncertainty (EPUC) indicates that Shanghai market rather economically has closer relationship with domestic EPU and foreign EPUs than Shenzhen market does according to higher cross-sectional coefficients between SHCOMP with EPUC, EPUE, and EPUS which are $0.4742,0.5341$, and 0.2430 in respectively that obtained 99 percent of confidence of the correlations. However, the correlation between Shanghai and Shenzhen market is quite high with 0.7 of their significant value of coefficient. Furthermore, it was revealed that all economic policy uncertainty indices have the significant correlation with others one as displayed in the last three columns showing that EPUC has correlations, respectively with EPUE by 
0.6876 and EPUS 0.4784 of coefficient. Meanwhile, the relationship between the economic policy uncertainty in Europe (EPUE) and the US (EPUS) resulted in their correlation by 0.6928 of coefficient.

In order to test whether economic policy uncertainty from our sample have significant causes or ability to forecast among each other or not, we obtain Granger causality test result as display in Table 4.

Table 4. Granger causality test for the EPUs

\begin{tabular}{lcl}
\hline Null Hypothesis: & F-Statistic & P-value. \\
\hline EPUE does not Granger Cause EPUC & 5.60563 & $0.0041^{* * *}$ \\
EPUC does not Granger Cause EPUE & 4.33483 & $0.0140^{* *}$ \\
EPUS does not Granger Cause EPUC & 5.81933 & $0.0033^{* * *}$ \\
EPUC does not Granger Cause EPUS & 4.24046 & $0.0153^{* *}$ \\
EPUS does not Granger Cause EPUE & 1.97728 & 0.1403 \\
EPUE does not Granger Cause EPUS & 3.72065 & $0.0254^{* *}$ \\
\hline
\end{tabular}

Note: *,**, and *** in the table respectively represent the confidence levels at $90 \%, 95 \%$, and $99 \%$ to reject null hypothesis.

The economic policy uncertainty in China obviously causes the economic policy uncertainty in Europe and the United States. By the way, it is also caused by the EPU from these foreign regions due to F-statistics and P-Values to reject the null hypothesis of Granger causality test. As significant value does not occur in one test of a pair of economic policy uncertainty in the US and Europe, we therefore accept that the EPU from the US does not statistically cause the EPU in Europe. Although the EPU in the US does not significantly matter to the EPU in Europe, however, the result in the table still shows the significant value to reveal that the EPU in Europe statistically cause the economic policy in the United States.

\subsection{VAR (2) Estimations.}

In this study, lag $p=2$ or VAR (2) is the ultimate estimation according to lag length selection criteria purposed in our methodology. Nevertheless, in order to fit the stationary VA, an ADF unit root test was processed to check all of our variables and the stationary was found at the fist difference. Since that, all variables are therefore transformed to be the first differentiated time series data represented by D(CSI300), D(SHCOMP), D(SZCOMP), D(EPUC), D(EPUE) D(EPUS) with the estimation result of VAR (2) shown in Table 5.

From VAR estimation with 2 lags in Table 5, it resulted that the differences of Shanghai composite index (D(SHCOMP)), Shenzhen composite index (D(SZCOMP)), and their weighted index (D(CSI300)) significantly correlate to their autoregressions at the past two periods (second lag) with the value of coefficients at $-0.2721,-0.6064$, and -0.5832 in respectively. At the meantime, they also significantly correlate with the difference of China's EPU (D(EPUC)) at one past period (first lag) with negative coefficient of -0.3798 for D(SHCOMP), -0.6956 for $\mathrm{D}$ (SZCOMP), and -0.8379 for D(CSI300). In addition, China's EPU is statistically significant with itself and the EPU in Europe (D(EPUE)) at the first and second lags. And finally, the correlation between the difference of economic policy uncertainty in the United States (D(EPUS)) and Chinese stock markets has significant measurement in Shenzhen at lag 2 while D(EPUE) statistically has a significance only with the difference of weighted index D(CSI300). The interpretation regarding the significant result from this VAR (2) leads us to find the endogeneity among the variables so that to forecast each other particularly using the first and second lag to determine their autoregressive process. 
Table 5. VAR (2) estimates

\begin{tabular}{|c|c|c|c|c|c|c|}
\hline Variables & $\mathrm{D}(\mathrm{CSI} 300)$ & $\mathrm{D}$ (SHCOMP) & $\mathrm{D}$ (SZCOMP) & $\mathrm{D}$ (EPUC) & D(EPUE) & US) \\
\hline \multirow{2}{*}{$\mathrm{D}(\mathrm{CSI} 300(-1))$} & 0.33981 & 0.09902 & 0.27004 & -0.07742 & 0.05000 & 0.04147 \\
\hline & [ 0.95029$]$ & [ 0.63300$]$ & {$[0.81410]$} & {$[-0.80991]$} & [ 0.93163$]$ & [ 0.86327$]$ \\
\hline \multirow[t]{2}{*}{$\mathrm{D}(\operatorname{CSI} 300(-2))$} & -0.01261 & 0.06369 & $0.05450^{*}$ & -0.14418 & $-0.10619 * *$ & $-0.14356^{* * *}$ \\
\hline & {$[-0.03561]$} & [ 0.41096] & [ 0.16584$]$ & {$[-1.52247]$} & [-1.99713] & {$[-3.01633]$} \\
\hline \multirow[t]{2}{*}{$\mathrm{D}(\operatorname{SHCOMP}(-1))$} & -0.03310 & 0.01664 & -0.04227 & 0.02102 & -0.00054 & -0.01072 \\
\hline & {$[-0.10987]$} & [ 0.12625$]$ & {$[-0.15124]$} & [ 0.26102$]$ & [-0.01204] & {$[-0.26491]$} \\
\hline \multirow[t]{2}{*}{$\mathrm{D}(\operatorname{SHCOMP}(-2))$} & $-0.58324 * *$ & $-0.27210 * *$ & $-0.60648 * *$ & 0.07437 & 0.06891 & 0.05105 \\
\hline & {$[-1.96937]$} & {$[-2.10019]$} & {$[-2.20755]$} & [ 0.93935$]$ & [ 1.55012$]$ & [ 1.28301$]$ \\
\hline \multirow[t]{2}{*}{ D(SZCOMP(-1)) } & -0.31416 & -0.05863 & -0.22103 & 0.05644 & -0.06002 & -0.04125 \\
\hline & {$[-0.82588]$} & {$[-0.35235]$} & {$[-0.62639]$} & [ 0.55502$]$ & [-1.05116] & {$[-0.80721]$} \\
\hline \multirow[t]{2}{*}{$\mathrm{D}(\operatorname{SZCOMP}(-2))$} & 0.40594 & 0.06636 & 0.34938 & 0.12845 & 0.09181 & $0.13953^{* * *}$ \\
\hline & [ 1.07624$]$ & [ 0.40219$]$ & [ 0.99853] & [ 1.27384$]$ & [ 1.62171$]$ & [ 2.75343] \\
\hline \multirow[t]{2}{*}{$\mathrm{D}(\operatorname{EPUC}(-1))$} & $-0.83792^{* * *}$ & $-0.37981 * * *$ & $-0.69562 * *$ & $-0.41676^{* * *}$ & -0.02755 & 0.04080 \\
\hline & {$[-2.55179]$} & {$[-2.64402]$} & {$[-2.28366]$} & {$[-4.74748]$} & {$[-0.55897]$} & [ 0.92483] \\
\hline \multirow[t]{2}{*}{$\mathrm{D}(\mathrm{EPUC}(-2))$} & -0.48029 & -0.19408 & -0.43185 & $-0.25669^{* * *}$ & -0.00445 & 0.03126 \\
\hline & {$[-1.45688]$} & {$[-1.34575]$} & {$[-1.41210]$} & {$[-2.91253]$} & {$[-0.09000]$} & [ 0.70579] \\
\hline \multirow[t]{2}{*}{ D(EPUE(-1)) } & 0.29938 & 0.20937 & 0.20260 & $0.32605^{*}$ & $-0.37052^{* * *}$ & -0.05899 \\
\hline & [ 0.44570$]$ & [ 0.71249] & [ 0.32513] & [ 1.81568$]$ & {$[-3.67506]$} & {$[-0.65361]$} \\
\hline \multirow[t]{2}{*}{$\mathrm{D}(\operatorname{EPUE}(-2))$} & 0.72759 & 0.30902 & 0.93021 & $0.51527 * * *$ & $-0.20294 * *$ & 0.01545 \\
\hline & [ 1.06838$]$ & [ 1.03726$]$ & [ 1.47244$]$ & [ 2.83016] & [-1.98535] & [ 0.16889] \\
\hline \multirow[t]{2}{*}{ D(EPUS(-1)) } & -0.45473 & -0.27087 & -0.49251 & 0.29722 & 0.14502 & $-0.24978^{* * *}$ \\
\hline & {$[-0.64166]$} & {$[-0.87372]$} & {$[-0.74918]$} & [ 1.56879$]$ & [ 1.36340$]$ & {$[-2.62333]$} \\
\hline \multirow[t]{2}{*}{$\mathrm{D}(\operatorname{EPUS}(-2))$} & -0.59122 & -0.30989 & -0.71881 & -0.15046 & -0.05017 & $-0.28093 * * *$ \\
\hline & {$[-0.82671]$} & {$[-0.99052]$} & {$[-1.08353]$} & {$[-0.78699]$} & {$[-0.46739]$} & {$[-2.92375]$} \\
\hline \multirow[t]{2}{*}{ Constant } & 17.21282 & 7.93492 & 11.44129 & 8.03509 & 1.81352 & 1.26791 \\
\hline & {$[0.76670]$} & [ 0.80793$]$ & [ 0.54937$]$ & [ 1.33876$]$ & [ 0.53819$]$ & [ 0.42035$]$ \\
\hline
\end{tabular}

Notes: Numbers in brackets [-] refer to the t-statistics. *,**, and *** in the table represent the confidence levels at $90 \%$, $95 \%$, and $99 \%$ in respectively.

\subsection{Residuals and Impulse Responses}

The residuals from VAR in Figure 3 show the dramatic drops in Shanghai and Shenzhen markets especially in Shenzhen market where the effect is likely to be greater than Shanghai market during the financial crisis (2007-2008) and in 2015, while EPU in China, Europe, and the United States were increasing at the time. Furthermore, impulse responses provided in Figure 4 demonstrate both of Chinese markets negatively respond to the domestic EPU and the EPU from the US, straightway in the first month and starting to adjust into equilibrium in the next month, and finally equilibrate themselves within the third month. However, the responses of the Chinese markets to the EPU in Europe are quite different as the Chinese markets barely respond in the first month to the EPUE but there will be lightly positive response in 1.5 months after EPUE shocks in Shanghai and about two months in Shenzhen switching to negative responses before adjusting to the balance in the fifth month (see also Figure 5 and Figure 6 in Appendix for the rest responses of three markets and EPUs). 
D(CSI300) Residuals

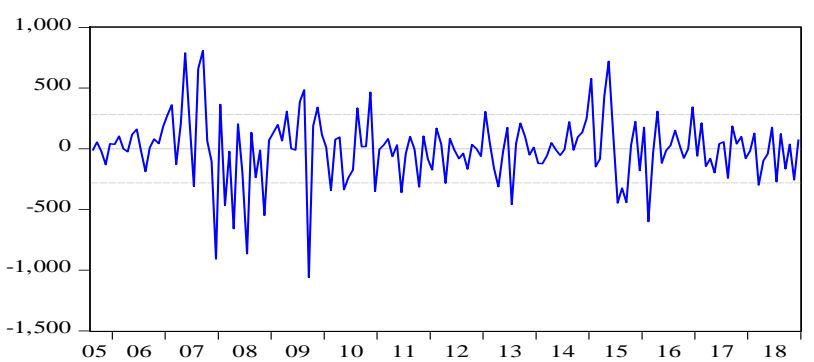

D(SZCOMP) Residuals

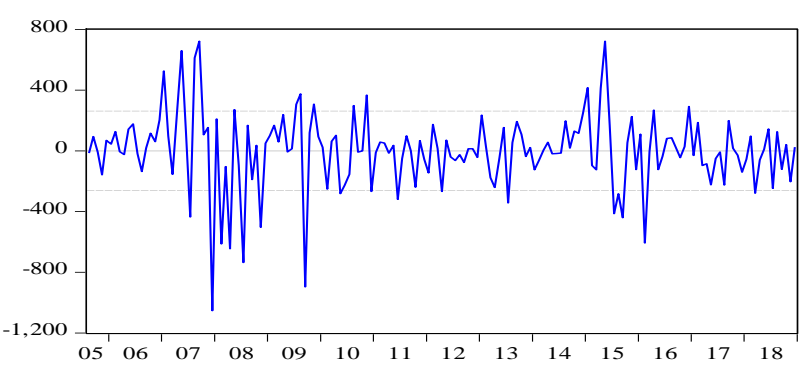

D(SHCOM P) Residuals

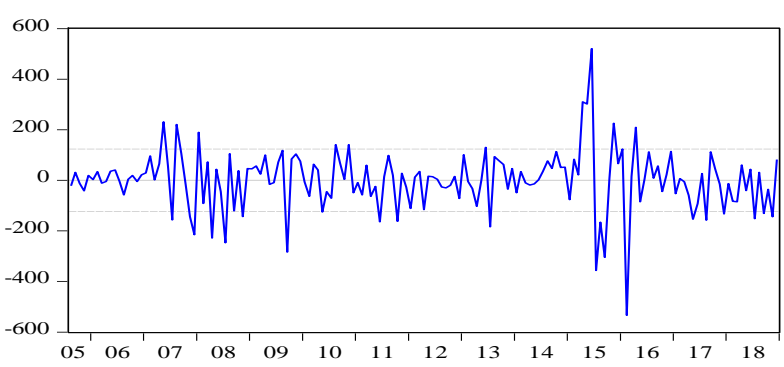

D(EPUC) Residuals

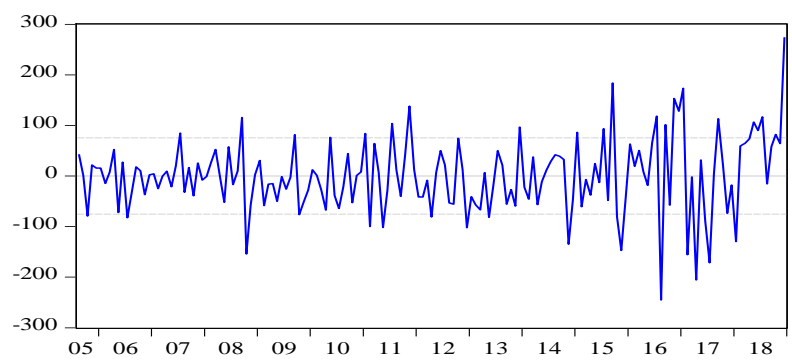

D(EPUE) Residuals

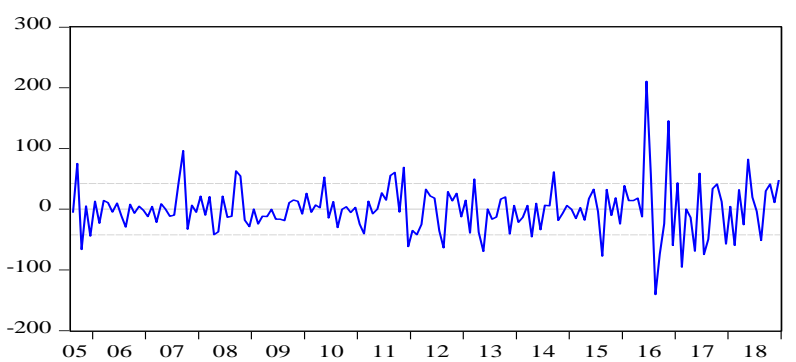

D(EPUS) Residuals

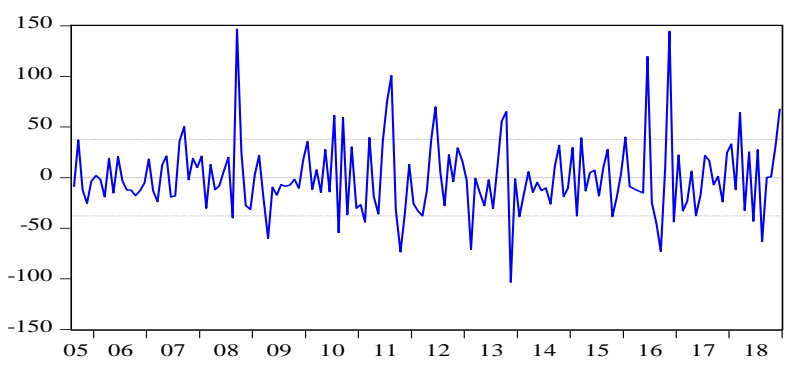

Figure 3. VAR Residuals 
Response ofD(CSI300) to D(EPUC)

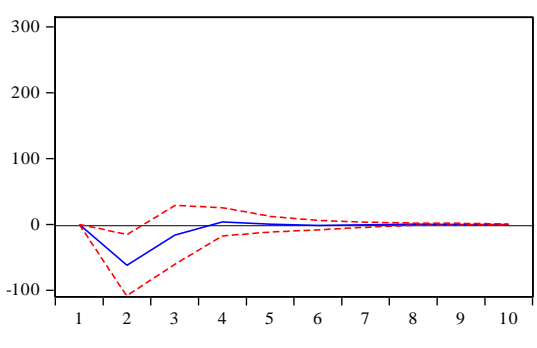

Response ofD(SHCOMP) to D(EPUC)

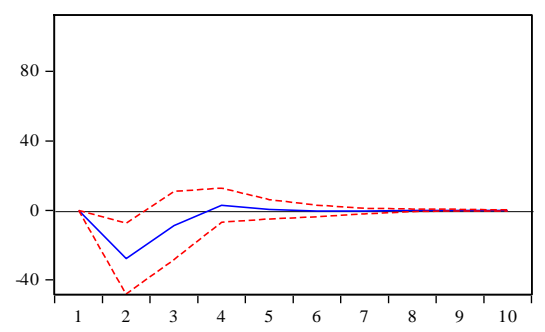

Response ofD(SZCOMP) to D(EPUC)

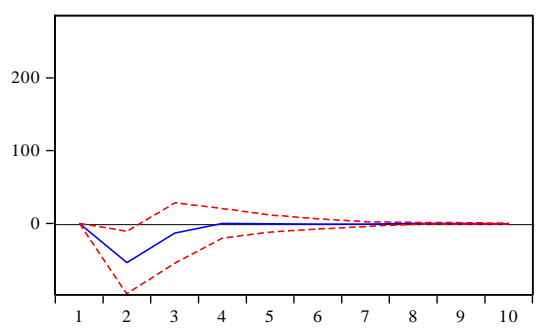

Response ofD(CSI300) to D(EPUE)
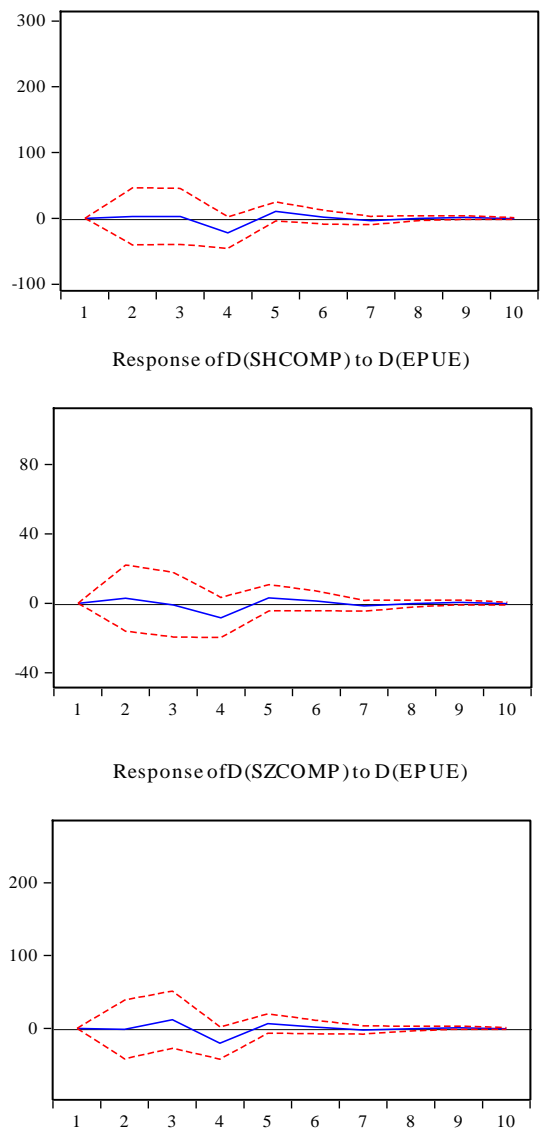

Response ofD(CSI300) to D(EPUS)
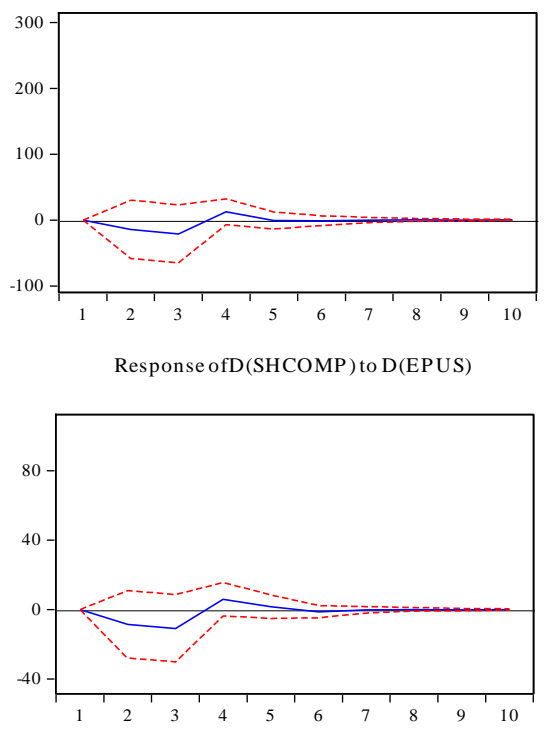

Response ofD(SZCOMP) to D(EPUS)

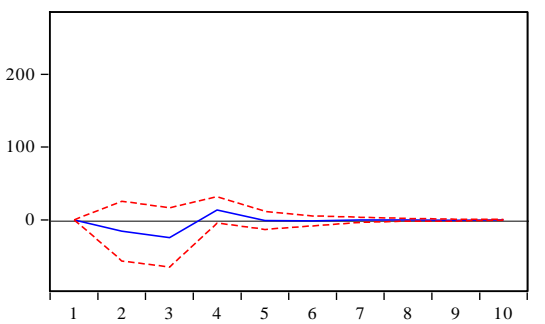

Figure 4. Impulse responses of Chinese stock markets to the EPUs

\section{Discussion}

The relationship between China and the United States has been more emphasized in many literatures that mostly found negative responses from economic sectors to the economic policy uncertainty. The reason of using VAR model in this study is regarding to our related literatures review that aim to analyze the responses of interesting endogenous variables which could be obtained by VAR process.

According to our findings, we firstly found sharp increasing of the economic policy uncertainty in China and the US during an incidence of China-US trade war from economic policy uncertainty index graph plots (Figure 1). Then, the significant coefficients obtained from a linear regression in equation (10) indicate around 58 to 65 percent of the Chinese EPU is mainly determined by trade and fiscal policy uncertainty. It let us consider about an effect of China-US trade war that has brought an increasing in economic policy uncertainty in the two countries. This existence of the impact from trade war is recognized by a significant positive cross-sectional correlation between economic policy uncertainty index in China and the US. In consequence, Granger's causality test was applied to confirm the robustness of the relationship between economic policy uncertainty in both countries so that we found the significant causes between the EPU in China and the US that are related to trade war.

Although negative responses of the stock market to the EPU were found in most of related literatures, however, unlike others, we surprisingly found the positive responses of the Chinese markets to the EPU from Europe with significance while responses to domestic and the US EPU remain negative. This indicates that Chinese stock markets could gain some profit from an increasing of economic policy uncertainty in Europe. In our point of view, when Europe faces higher economic policy certainty, capital may move to the stock markets in China in order to seeking for better expected returns from the Chinese stock markets. Moreover, residuals and impulse responses from our VAR (2) process reveal greater effects in Shenzhen stock market rather than in Shanghai. However, this result is not consistent with Xiong et al. (2018) where greater effect of the EPU was taken by Shanghai stock market. 


\section{Conclusion}

Based on VAR (2) results, China's economic policy uncertainty in lag 2 statistically depresses both Chinese stock markets as well as their weighted index performance. It is also incidentally relevant to the economic policy uncertainty from Europe, and the United States via significant crossed-correlations among each other that confirmed by Granger causality test.

An increase in economic policy in China and the US significantly affects negative responses on the Chinese stock markets especially in Shenzhen market where the size of effect appears to be greater than responses from Shanghai. The Chinese markets take longer responses to the EPU shocks from the US by five months while taking shorter (three months) responding after EPU shocks from China until balancing. However, EPU from Europe is likely to benefit the Chinese markets as the two markets positively respond to the EPUE at the first place. However, these responses are switching and swing to negative responses before market adjustment.

Furthermore, major influent factors of China's EPU are their domestic uncertainty in trade and fiscal policy regarding our ordinary linear regression that may therefore be related to the inauguration of Donald Trump and China-US trade war so that we can give our opinion that Chinese stock markets negatively and directly respond to the domestic EPU with roundabout foreign EPU from Europe and the United States.

\section{References}

Arouri, M., Estay, C., Rault, C., \& Roubaud, D. (2016). Economic policy uncertainty and stock markets: Long-run evidence from the US. Finance Research Letters, 18(2016), 136-141. https://doi.org/10.1016/j.frl.2016.04.011

Bachman, R., Elstner, S., \& Sims, E. R. (2013). Uncertainty and Economic Activity: Evidence from Business Survey Data. AMERICAN ECONOMIC JOURNAL: MACROECONOMICS, 5(2), 217-249. https://www.jstor.org/stable/43189547

Baker, R. S., Bloom, N., Davis, S. J., \& Wang, X. (2013). A measure of economic policy uncertainty for China, Work in progress, University of Chicago. Retrieved from http://www.policyuncertainty.com/scmp_monthly.html

Baker, R. S., Bloom, N., \& Davis, S. J. (2016). Measuring Economic Policy Uncertainty. The Quarterly Journal of Economics, 131(4), 1593-1636. https://doi.org/10.1093/qje/qjw024

Baker, R. S., Bloom, N., Davis, S. J., \& Kostd, K. (2019). Policy News and Stock Market Volatility. Working Paper No. 2019-53, University of Chicago. http://dx.doi.org/10.2139/ssrn.3363862

Biljanovska, N., Grigoli, F., \& Hengge, M. (2017). Fear Thy Neighbor: Spillovers from Economic Policy Uncertainty. IMF Working Paper, No. WP/17/240. Retrieved from

https://www.imf.org/en/Publications/WP/Issues/2017/11/15/Fear-Thy-Neighbor-Spillovers-from-Economic-PolicyUncertainty-45346

Christou, C., Cunado, J., Gupta, R., \& Hassapis, C. (2017). Economic policy uncertainty and stock market returns in PacificRim countries: Evidence based on a Bayesian panel VAR model. Journal of Multinational Financial Management, 40, 92-102. https://doi.org/10.1016/j.mulfin.2017.03.001

Chen, J., Jiang, F., \& Tong, G. (2017). Economic policy uncertainty in China and stock market expected returns. Accounting \& Finance, 57, 1265-1286. https://doi.org/10.1111/acfi.12338

Debata, B., \& Mahakud, J. (2018). Economic policy uncertainty and stock market liquidity: Does financial crisis make any difference? Journal of Financial Economic Policy, 10(1), 112-135. https://doi.org/10.1108/JFEP-09-2017-0088

Fang, L., Yu, H., \& Li, L. (2017). The effect of economic policy uncertainty on the long-term correlation between U.S. stock and bond markets. Economic Modelling, 66, 139-145. https://doi.org/10.1016/j.econmod.2017.06.007

Fontaine, I., Didier, L., \& Razafindravaosolonirina, J. (2017). Foreign policy uncertainty shocks and US macroeconomic activity: Evidence from China. Economics Letters, 155, 121-125.

https://doi.org/10.1016/j.econlet.2017.03.034

Hamilton, J. D. (1994). Time Series Analysis. Princeton University Press, Princeton.

Jurado, K., Sydney, C. L., \& Serena, Ng. (2015). Measuring Uncertainty. American Economic Review, 105(3), 1177-1216. https://doi.org/10.1257/aer.20131193

Li, X. M., \& Peng, L. (2017). US economic policy uncertainty and co-movements between Chinese and US stock markets. Economic Modelling, 61, 27-39. https://doi.org/10.1016/j.econmod.2016.11.019

Liu, L., \& Zhang, T. (2015). Economic policy uncertainty and stock market volatility. Finance Research Letters, 15, 
99-105. https://doi.org/10.1016/j.frl.2015.08.009

Pastor, L., \& Veronesi, P. (2013). Political uncertainty and risk premia. Journal of Financial Economics, 110, 520-545. https://doi.org/10.1016/j.jfineco.2013.08.007

Sims, C. A. (1980). Macroeconomics and Reality. Econometrica, 48, 1-48. https://doi.org/10.2307/1912017

Sum, V. (2012). Economic Policy Uncertainty and Stock Market Returns. International Review of Applied Financial Issues and Economics, Forthcoming. Retrieved from http://dx.doi.org/10.2139/ssrn.2073184

Sum, V. (2012). Economic Policy Uncertainty and Stock Market Performance: Evidence from the European Union, Croatia, Norway, Russia, Switzerland, Turkey and Ukraine. Journal of Money, Investment and Banking, 25, 99-104. http://dx.doi.org/10.2139/ssrn.2094175

Wang, Y., Chen, C. R., \& Huang, Y. S. (2014). Economic policy uncertainty and corporate investment: Evidence from China. Pacific-Basin. Finance Journal, 26, 227-243. https://doi.org/10.1016/j.pacfin.2013.12.008

Xiong, X., Bian, Y., \& Shen, D. (2018). The time-varying correlation between policy uncertainty and stock returns: Evidence from China. Physica A, 499, 413-419. https://doi.org/10.1016/j.physa.2018.02.034

Yun, H., \& Luk, P. (2018). Measuring Economic Policy Uncertainty in China. Working paper. Retrieved from https://economicpolicyuncertaintyinchina.weebly.com/uploads/1/2/2/7/122762465/measuring_economic_policy_u ncertainty_in_china.pdf

Zhang, D., Lei, L., Ji, Q., \& Kutan, A. M. (2018). Economic policy uncertainty in the US and China and their impact on the global markets. Economic Modelling, 79(C), 47-56.

https://ideas.repec.org/a/eee/ecmode/v79y2019icp47-56.html 


\section{Appendix}

Response of D(CSI300) to D(CSI300)

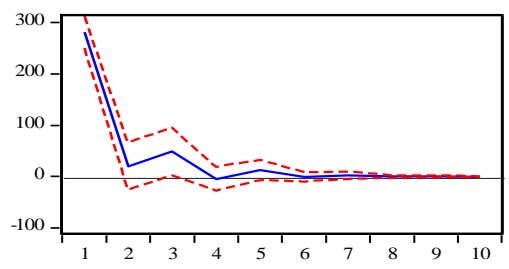

Response of D(SHCOMP) to D(CSI300)

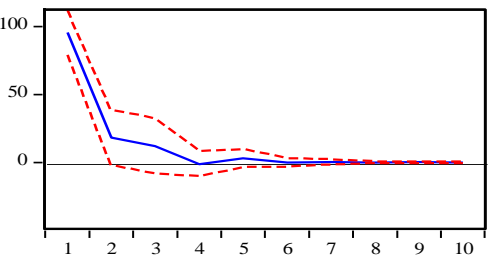

Response of D(SZCOMP) to D(CSI300)

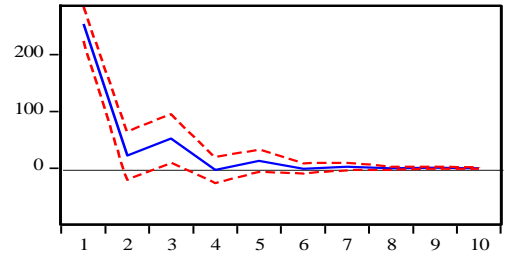

Response of D(EPUC) to D(CSI300)

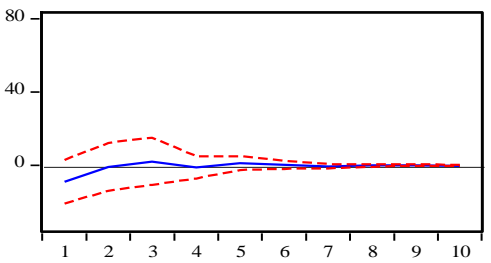

Response of D(EPUE) to D(CSI300)

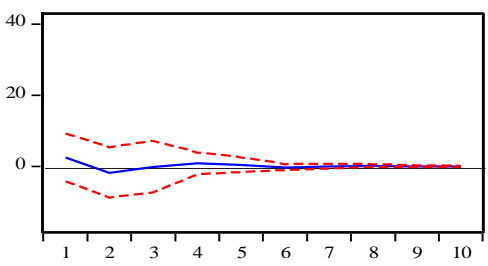

Response of D(EPUS) to D(CSI300)

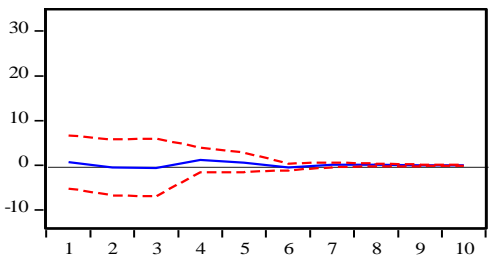

Response of D(CSI300) to D(SHCOMP)

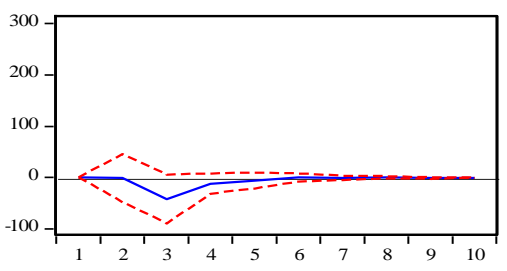

Response of D(SHCOMP) to D(SHCOMP)

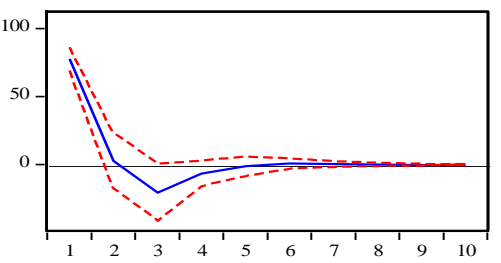

Response of D(SZCOMP) to D(SHCOMP)

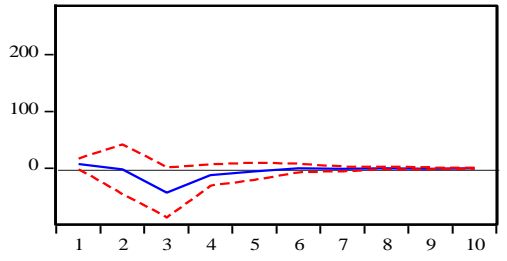

Response of D(EPUC) to D(SHCOMP)

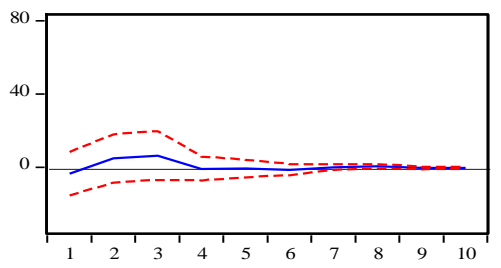

Response of D(EPUE) to D(SHCOMP)

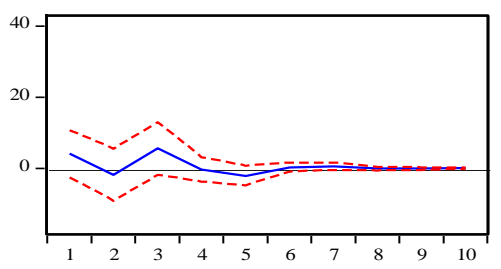

Response of D(EPUS) to D(SHCOMP)

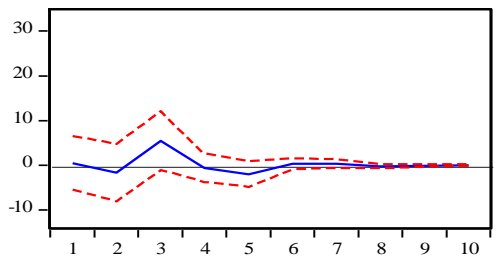

Response of D(CSI300) to D(SZCOMP)

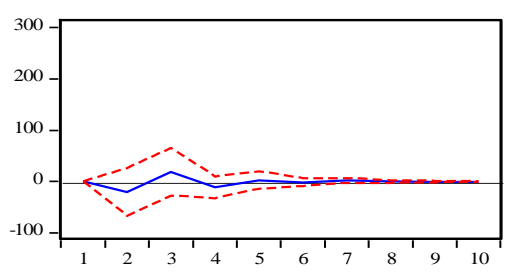

Response of D(SHCOMP) to D(SZCOMP)

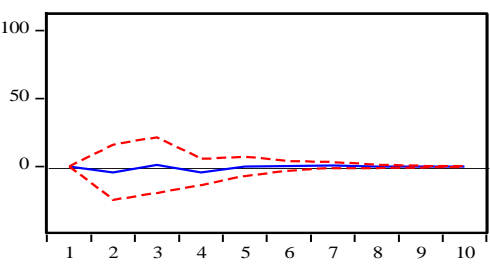

Response of D(SZCOMP) to D(SZCOMP)

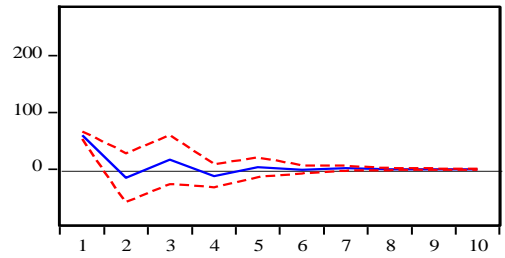

Resp on se of D(EPUC) to D(SZCOMP)

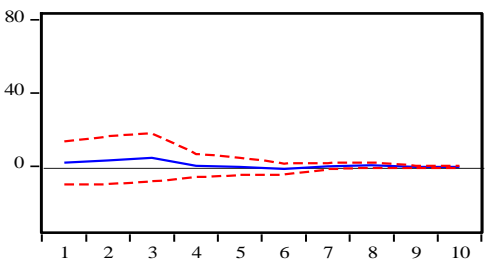

Response of D(EPUE) to D(SZCOMP)

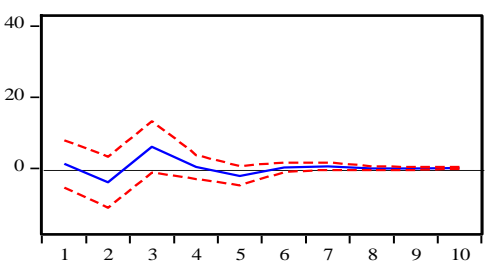

Response of D(EPUS) to D(SZCOMP)

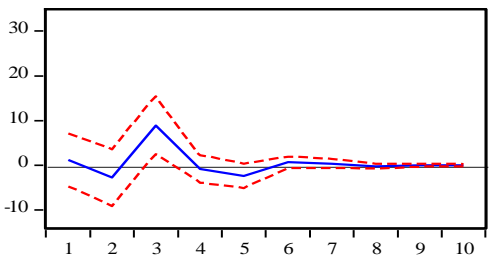

Figure 5. Impulse responses to the markets 

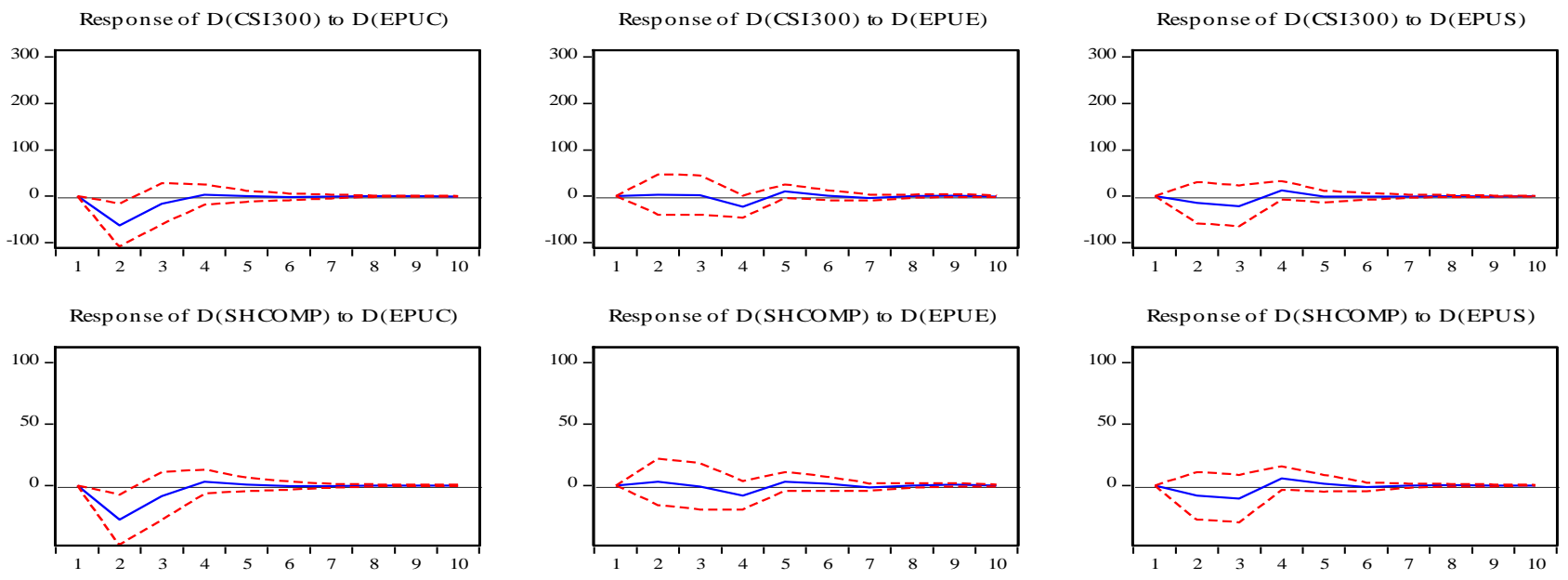

Response of D(SZCOMP) to D(EPUC)

Response of D(SZCOMP) to D(EPUE)
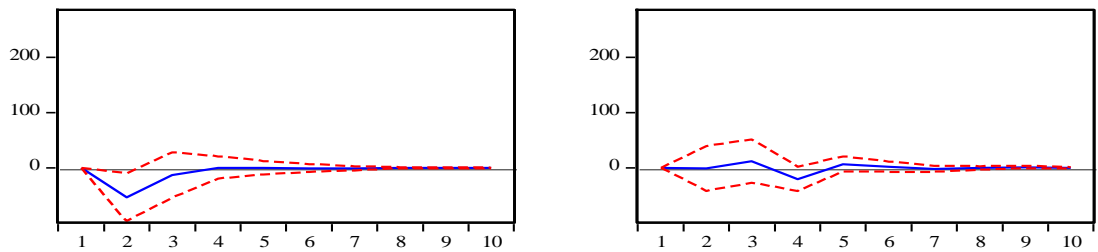

Response of D(SZCOMP) to D(EPUS)

Response of D(EPUC) to D(EPUC)

Response of D(EPUC) to D(EPUE)
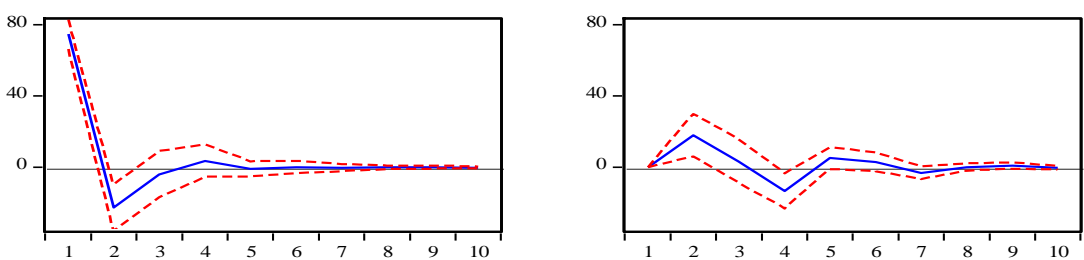

Response of D(EPUC) to D(EPUS)

Response of D(EPUE) to D(EPUC)

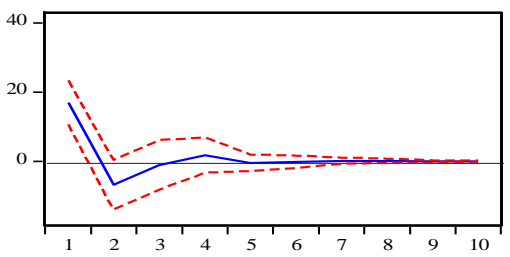

Response of D(EPUE) to D(EPUE)

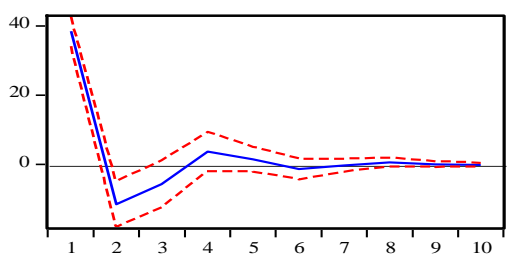

Response of D(EPUE) to D(EPUS)

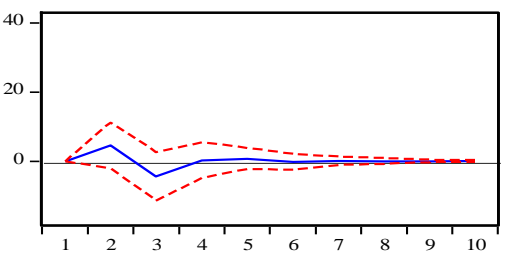

Response of D(EPUS) to D(EPUE)

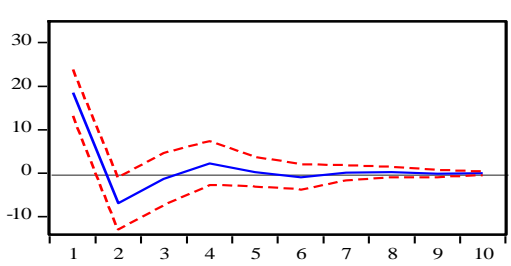

Response of D(EPUS) to D(EPUS)

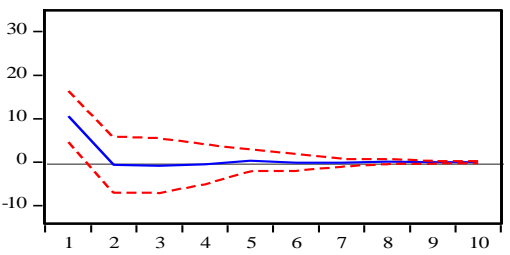

Figure 6. Impulse responses to EPUs

\section{Copyrights}

Copyright for this article is retained by the author(s), with first publication rights granted to the journal.

This is an open-access article distributed under the terms and conditions of the Creative Commons Attribution license which permits unrestricted use, distribution, and reproduction in any medium, provided the original work is properly cited. 